\title{
Ribonuclease from Bacillus Acts as an Antiviral Agent against Negative- and Positive-Sense Single Stranded Human Respiratory RNA Viruses
}

\author{
Raihan Shah Mahmud, ${ }^{1}$ Christin Müller, ${ }^{2}$ Yulia Romanova, ${ }^{1}$ Ahmed Mostafa, ${ }^{2,3}$ \\ Vera Ulyanova, ${ }^{1}$ Stephan Pleschka, ${ }^{2}$ and Olga Ilinskaya ${ }^{1}$ \\ ${ }^{1}$ Institute of Fundamental Medicine and Biology, Kazan Federal University, Kremlevskaya Street 18, Kazan 420008, Russia \\ ${ }^{2}$ Institute of Medical Virology, Justus Liebig University, Schubert Street 81, 35392 Giessen, Germany \\ ${ }^{3}$ Center of Scientific Excellence for Influenza Viruses, National Research Centre (NRC), El-Buhouth Street 87, Dokki, Cairo 12311, Egypt
}

Correspondence should be addressed to Raihan Shah Mahmud; raihan.shah@gmail.com

Received 6 January 2017; Accepted 4 April 2017; Published 4 May 2017

Academic Editor: Syed Abdul Qadir

Copyright (C) 2017 Raihan Shah Mahmud et al. This is an open access article distributed under the Creative Commons Attribution License, which permits unrestricted use, distribution, and reproduction in any medium, provided the original work is properly cited.

\begin{abstract}
Bacillus pumilus ribonuclease (binase) was shown to be a promising antiviral agent in animal models and cell cultures. However, the mode of its antiviral action remains unknown. To assess the binase effect on intracellular viral RNA we have selected single stranded negative- and positive-sense RNA viruses, influenza virus, and rhinovirus, respectively, which annually cause respiratory illnesses and are characterized by high contagious nature, mutation rate, and antigen variability. We have shown that binase exerts an antiviral effect on both viruses at the same concentration, which does not alter the spectrum of A549 cellular proteins and expression of housekeeping genes. The titers of influenza A $(\mathrm{H} 1 \mathrm{~N} 1 \mathrm{pdm})$ virus and human rhinovirus serotype $1 \mathrm{~A}$ were reduced by $40 \%$ and $65 \%$, respectively. A preincubation of influenza virus with binase before infection significantly reduced viral titer after single-cycle replication of the virus. Using influenza A virus mini genome system we showed that binase reduced GFP reporter signaling indicating a binase action on the expression of viral mRNA. Binase reduced the level of H1N1pdm viral NP mRNA accumulation in A549 cells by $20 \%$. Since the viral mRNA is a possible target for binase this agent could be potentially applied in the antiviral therapy against both negative- and positive-sense RNA viruses.
\end{abstract}

\section{Introduction}

The single stranded RNA viruses, such as negative-sense Ebola, Marburg, Lassa, and influenza and positive-sense human immunodeficiency viruses, are very important human pathogens in the world. Recent virus outbreaks with a large number of human deaths were caused by RNA viruses like Ebola, corona, Zika, and different strains of influenza A viruses. Among RNA viruses, the respiratory viruses are highly contagious and cause annually worldwide epidemics and occasional pandemic outbreaks. The influenza A virus even without a pandemic outbreak kills up to half million humans each year. A great number of diseases are attributable to human rhinoviruses (HRV) which are the major cause of the common cold. HRV infections are suffered by everyone. Recent reports suggest that HRV infection is associated with severe respiratory illness in children [1].

The main problem of antiviral therapy is drug resistance. Although the majority of common viral diseases are selflimited illnesses that do not require specific antiviral therapy, antiviral drugs help to prevent complications or shorten the severity and duration of viral diseases symptoms. Considerable economic losses from annual epidemics promote constant search for new antiviral agents, which become useless with time due to the high variability of viruses.

Usually, two groups of drugs are used for the treatment of influenza. The first group including rimantadine and its analogs inhibits the ion channel function of M2 protein, 
thereby inhibiting viral uncoating. The second one represented by oseltamivir inhibits the enzyme neuraminidase [3]. Inducing adaptive immunity through the vaccination with inactivated or attenuated antigenic material of viruses helps to prevent influenza illness or to reduce its impact in individuals. There is no permanent vaccination against influenza virus and each year countries lose a large amount of money from their budget to prepare new vaccines and rescue the national public health and life. Widespread antiviral resistance due to the high mutation rate in viral genome limits the clinical impact of all types of medicinal products for the prevention and treatment of influenza infections.

Currently, there is no vaccine against HRV [1]. The HRV has almost the highest number of serotypes (more than 100) among all respiratory viruses due to mutations of its genome. Antigenic heterogeneity of HRVs is regarded as a major barrier to effective vaccine development which has to be highly polyvalent and has resulted in little progress over 50 years [1, 4]. Other problems, which have impeded rhinoviral vaccine development, include the lack of convenient animal models and as expected the absence of great impact on respiratory morbidity and mortality while reducing the frequency of common colds [5]

Today, there are no drugs that destroy viruses; all antiviral agents can only inhibit viral development. Therefore, degradation of the viral RNA seems to be a very promising approach of antiviral therapy. The earliest studies on the antiviral activity of RNases were performed using pancreatic RNase as an agent that quickly normalized the state and decreased the symptoms of meningitis and cerebrospinal pleocytosis in patients with tick borne encephalitis [6]. Shortcoming of mammalian RNases is their affinity to cytosolic RNase inhibitor protein (RI) in human cells by which adventitious mammalian RNases are inhibited. In contrast, bacterial RNases are not inhibited by RI and can retain their catalytic activity in mammalian tissues. One of the wellstudied bacterial RNases is binase, the guanyl-preferring low molecular weight RNase secreted by Bacillus pumilus [7].

We proposed earlier that mechanisms of antiviral activity of RNases include both the direct action on nucleic acid and indirect effects, that is, intervention into the RNA interference, immunomodulation, and induction of infected cell apoptosis (for review see [8]). We have demonstrated that binase reduced the titer of pandemic influenza A/Hamburg/4/2009 (H1N1pdm), reovirus serotype 1 (Reo 1-Lang), herpes virus type I (pseudorabies), Middle East respiratory syndrome coronavirus (MERS-CoV), and human corona virus (HCoV-229E) in infected Madin-Darby canine kidney (MDCK) epithelial cells, African green monkey kidney (Vero) cells, Madin-Darby bovine kidney (MDBK) epithelial cells, human fetal lung fibroblast (MRC5) cells, and hepatocellular carcinoma (Huh7) cells, respectively [911]. Influenza viruses contain single stranded negative-sense RNA; reoviruses have a double stranded RNA genome, while herpes virus possesses genomic DNA. Because of the specific catalytic activity of binase towards RNA (mainly single stranded) and its inhibitory effect towards RNA- and DNAcontaining viruses, it could be proposed that this enzyme should affect mRNA, which is synthesized by all viruses. The aim of our study was to prove that viral mRNA is a direct target of binase.

\section{Materials and Methods}

2.1. Cells, Viruses, and Stocks. A546 (human lung adenocarcinoma epithelial), HeLa (human cervical cancer), and MDCKII (Madin-Darby canine kidney epithelial) cells were cultured in growth Dulbecco's modified Eagle medium (DMEM) (Gibco, USA) supplemented with $10 \%$ fetal bovine serum (PAA, Austria), $100 \mathrm{U} / \mathrm{ml}$ penicillin, and $0.1 \mathrm{mg} / \mathrm{ml}$ streptomycin (P/S) (Gibco, USA) and incubated at $37^{\circ} \mathrm{C}$ in a $5 \% \mathrm{CO}_{2}$ atmosphere. The pandemic influenza A/Hamburg/04/09 (H1N1pdm) and human rhinovirus serotype 1A (HRV1A) were provided by the strain collection of the Institute of Medical Virology, Justus Liebig University, Giessen, Germany, and propagated in MDCK-II and HeLa cells, respectively. Briefly, MDCK-II and HeLa monolayers were incubated with H1N1pdm and HRV1A at a multiplicity of infection (MOI) of 1 diluted in $\mathrm{PBS}^{++} / \mathrm{BA}$ (PBS containing $0.2 \%$ bovine albumin (PAA, Germany), $1 \mathrm{mM} \mathrm{MgCl}_{2}, 0.9 \mathrm{mM}$ $\mathrm{CaCl}_{2}, 100 \mathrm{U} / \mathrm{ml}$ penicillin, and $0.1 \mathrm{mg} / \mathrm{ml}$ streptomycin). After $1 \mathrm{~h}$ of virus adsorption in the dark, the cell monolayers were supplemented with medium and incubated at either $37^{\circ} \mathrm{C}(\mathrm{H} 1 \mathrm{~N} 1 \mathrm{pdm})$ or $33^{\circ} \mathrm{C}(\mathrm{HRV} 1 \mathrm{~A})$ in humidified $5 \% \mathrm{CO}_{2}$ conditions.

2.2. Bacteria Growth Condition and Binase Isolation. Binase (EC 3.1.27.3; bacterial extracellular guanyl-preferring ribonuclease) was collected from the culture medium of Bacillus pumilus B3073 (the former name is B. intermedius B3073 [7]). The cultures were grown in a $1 \mathrm{~L}$ conical flask containing 1/5 flask volume of the phosphate deficient liquid medium (2.0\% low phosphate peptone, $1.0 \%$ glucose, $1.0 \% \mathrm{CaCl}_{2}, 0.3 \%$ $\mathrm{NaCl}, 0.03 \% \mathrm{MgSO}_{4} \times 7 \mathrm{H}_{2} \mathrm{O}$, and $0.01 \% \mathrm{MnSO}_{4}, \mathrm{pH} 8.5$ ) with $200 \mathrm{rpm}$ in a Multitron shaking incubator (INFORS HT, Switzerland) at $37^{\circ} \mathrm{C}$ until the beginning of the stationary phase of bacterial growth. After centrifugation at $6000 \mathrm{~g}$ for $30 \mathrm{~min}$, the pelleted bacterial cells were removed; the supernatant was acidified by glacial acetic acid to $\mathrm{pH} 5.0$, diluted 1:5 in double-distilled water $\left(\mathrm{ddH}_{2} \mathrm{O}\right)$, and applied on the column with DE-32 cellulose (Whatman, UK) equilibrated with $10 \mathrm{mM}$ sodium acetate buffer $(\mathrm{pH}$ 5.0). The flow through from DE-32 was transferred to column packed with phosphocellulose P11 (Whatman, UK) equilibrated with $10 \mathrm{mM}$ sodium acetate buffer $(\mathrm{pH} 5.0)$. The system was then equilibrated with $20 \mathrm{mM}$ sodium phosphate buffer $(\mathrm{pH}$ 7.0). Binase was eluted with $200 \mathrm{mM}$ sodium phosphate buffer ( $\mathrm{pH}$ 7.0). Further polishing purification of binase was performed using the UnoS column and BioLogic DuoFlow chromatography system (Bio-Rad, USA) equilibrated with $20 \mathrm{mM}$ sodium acetate buffer ( $\mathrm{pH}$ 5.0) and eluted using a linear gradient of $0-0.25 \mathrm{M} \mathrm{NaCl}$. Elution fractions of $5 \mathrm{ml}$ were collected. The protein samples were frozen overnight at $-20^{\circ} \mathrm{C}$, followed by freezing for $15 \mathrm{~min}$ at $-80^{\circ} \mathrm{C}$ and then lyophilized for $48 \mathrm{~h}$ at $-50^{\circ} \mathrm{C}$ under vacuum using a Labconco FreeZone 2.5 Liter Freeze Dry System (Labconco, USA). Homogeneity and authenticity of the purified enzyme were confirmed by PAAG electrophoresis, Western blotting, 
and MALDI TOF/TOF mass spectrometry on UltrafleXtreme (Bruker Corporation, Germany) as described in [12].

2.3. Enzymatic Activity of Binase. The ribonuclease activity of binase was registered by $260 \mathrm{~nm}$ absorbance measuring of the products of binase hydrolysis of high molecular weight yeast RNA. Binase was incubated in $0.25 \mathrm{M}$ Tris$\mathrm{HCl}$ buffer ( $\mathrm{pH} 8.5$ ) in the presence of $0.5 \mu \mathrm{g} / \mu \mathrm{l}$ RNA (final concentration) in a water bath for $15 \mathrm{~min}$ at $37^{\circ} \mathrm{C}$. The reaction was stopped by addition of ice cold $6.8 \%$ perchloric acid followed by incubation on ice bath for $10 \mathrm{~min}$ followed by centrifugation for $10 \mathrm{~min}$ at $12000 \mathrm{~g}$. The supernatant was diluted 1:20 in $\mathrm{ddH}_{2} \mathrm{O}$ and used for the $260 \mathrm{~nm}$ absorbance measurement using spectrophotometer SmartSpec Plus (BioRad, USA). One unit of ribonuclease activity corresponded to the quantity of enzyme that increased the extinction of acidsoluble products of RNA hydrolysis at $260 \mathrm{~nm}$ by 1 optical unit after incubation for $1 \mathrm{~h}$ at $37^{\circ} \mathrm{C}$, calculated per $\mathrm{ml}$ of the enzyme solution.

2.4. Ribonuclease Activity in Cell Culture Medium. To identify the enzymatic activity of binase, the growth medium from subconfluence (90-95\%) A549 cells in a 96-well plate (in triplicate) was replaced with $100 \mu \mathrm{g} / \mathrm{ml}$ binase (final concentration) containing complete DMEM and incubated for $48 \mathrm{~h}$ at $37^{\circ} \mathrm{C}$ in $5 \% \mathrm{CO}_{2}$. The supernatant (cell culture fluid) containing binase was collected to measure the binase activity using RNase activity assay as described before (see Section 2.3).

2.5. Cell Viability Measurement. The cytotoxic concentration $\left(\mathrm{CC}_{50}\right.$, the concentration of compound that causes death to $50 \%$ of viable cells) of HeLa cells under binase treatment was measured using MTT assay as described by Shah Mahmud and Ilinskaya [13]. Briefly, growth medium of subconfluence HeLa cells in a 96-well plate (in triplicate) was replaced with DMEM containing different concentration of binase (at final concentrations of $0.005-500 \mu \mathrm{g} / \mathrm{ml}$ ) and kept for $24 \mathrm{~h}$ at $33^{\circ} \mathrm{C}$ in a humidified $5 \% \mathrm{CO}_{2}$ incubator. After aspirating the media and washing with $\mathrm{PBS}^{++}$(phosphate-buffered saline containing $1 \mathrm{mM} \mathrm{MgCl} 2,0.9 \mathrm{mM} \mathrm{CaCl}_{2}$ ) the cells were left to recover for $60 \mathrm{~min}$ in growth medium and then replaced by $200 \mu \mathrm{l}$ of MTT-mix (growth DMEM medium containing $0.123 \mathrm{mg} / \mathrm{ml}$ of MTT-reagent $=1-(4,5-$ dimethylthiazol-2- yl $)-$ 3,5-diphenylformazan, Sigma Aldrich, USA). The cells were further incubated for $60 \mathrm{~min}$ at $37^{\circ} \mathrm{C}$ in $5 \% \mathrm{CO}_{2}$. After discarding the MTT-mix, the cells were fixed with 4\% PFA paraformaldehyde (Roth, Germany) for $30 \mathrm{~min}$ at RT (room temperature) and then the fixing solution was discarded. The cells were air dried for 10-15 min and the tetrazolium crystals were dissolved by adding $200 \mu \mathrm{l}$ of isopropanol to each well. The plates were shaken for $10 \mathrm{~min}$ and analyzed photometrically at $492 \mathrm{~nm}$ excitation in an ELISA reader EL808 (BioTek, USA). The MTT value of the binase nontreated control was used as $100 \%$. The percentage of cell viability after binase exposure was calculated as follows: percentage viability $=$ 100/(MTT value of control $\times$ MTT value of binase-treated sample). The $\mathrm{CC}_{50}$ was determined using GraphPad Prism
5.0 Software (GraphPad Software Inc., USA) by plotting the percentage of viable cells as a function of the compound concentration.

2.6. Binase Treatment. To determine the effect of $100 \mu \mathrm{g} / \mathrm{ml}$ binase against H1Nlpdm virus, the A549 monolayers were subcultured to prepare 96 -well plates $\left(10^{6}\right.$ cells/well, $\left.n=8\right)$. Following the overnight $90-95 \%$ confluency of the monolayers, the growth medium was removed and cell monolayers were washed with $\mathrm{PBS}^{++}$. Virus suspension containing H1Nlpdm with $\mathrm{MOI}=1$ diluted in $\mathrm{PBS}^{++} / \mathrm{BA}(50 \mu \mathrm{l})$ was added to each well and incubated for $1 \mathrm{~h}$ at RT. The viral supernatant was then removed and binase at a final concentration of 10 or $100 \mu \mathrm{g} / \mathrm{ml}$ in an infection medium (DMEM containing $100 \mathrm{U} \mathrm{ml}^{-1}$ penicillin, $100 \mu \mathrm{g} / \mathrm{ml}$ streptomycin, $0.2 \%$ BSA (PAA, Germany), and $1 \mu \mathrm{g} / \mathrm{ml}$ TPCK-treated trypsin) was added. The cells were incubated for $12 \mathrm{~h}$ and then the viral loads in the collected supernatants were estimated using focus assay as described in $[13,14]$. The cell monolayers were subjected to cellular total protein or RNA extractions for further investigations. The binase and virus preincubation for $45 \mathrm{~min}$ and infection and incubation steps were performed as previously described by Shah Mahmud and Ilinskaya [13].

2.7. Binase Effective Concentration Determination. The effective concentration $\left(\mathrm{EC}_{50}\right.$, the concentration of compound which reduces the virus titer by 50\%) of binase against HRV1A was determined in HeLa cells. The cells were grown in a 48 -well plate (in triplicate) overnight at $37^{\circ} \mathrm{C}$ and $5 \%$ $\mathrm{CO}_{2}$. Cell monolayers were then washed and infected with $75 \mu \mathrm{l}$ of virus suspension in $\mathrm{PBS}^{++} / \mathrm{BA}(\mathrm{MOI}=1)$ for $1 \mathrm{~h}$ at $33^{\circ} \mathrm{C}$. After removing the virus inoculum, cells were incubated with $250 \mu \mathrm{l}$ growth medium in each well containing different concentrations of binase (at final concentrations of $0.01-500 \mu \mathrm{g} / \mathrm{ml}$ ) for $24 \mathrm{~h}$, at $33^{\circ} \mathrm{C}$ and $5 \% \mathrm{CO}_{2}$. The supernatants containing HRV1A virus were assayed for their viral titers using plaque assay.

2.8. Virus Titration. The HRV1A titers were determined in a 24-well cell culture plate containing subconfluence (90-95\%) HeLa cell monolayers using plaque assay. Briefly, the HRV1A virus inoculum was diluted 1:10 in $\mathrm{PBS}^{++} / \mathrm{BA}$. The growth media from HeLa cells were removed and the cell monolayers were washed using $\mathrm{PBS}^{++}$. The diluted virus was added to each well and incubated for $1 \mathrm{~h}$ at $33^{\circ} \mathrm{C}$ and $5 \% \mathrm{CO}_{2}$ and then removed. $500 \mu \mathrm{l}$ of Avicel-media containing 1x MEM and $1.25 \%$ Avicel (FMC BioPolymer, Belgium) was added and cells were further incubated for $48 \mathrm{~h}$ at $33^{\circ} \mathrm{C}$ with $5 \% \mathrm{CO}_{2}$. After removal of the overlay media, the cell monolayers were washed with $\mathrm{PBS}^{++}$, stained with $0.1 \%$ crystal violet solution, further washed, and dried. The plaques corresponding to propagating viral particles were counted. The H1N1pdm titers were determined in MDCK-II using focus assay. To analyze the binase effect against H1N1pdm or HRV1A and identify the $\mathrm{EC}_{50}$ of binase, the plaques were counted and $\mathrm{PFU} / \mathrm{ml}$ was measured using MS Excel Software package. The PFU/ml values of the binase nontreated infected HeLa cells were used as $100 \%$. The $\mathrm{EC}_{50}$ was determined using GraphPad Prism 
5.0 Software (GraphPad Software Inc., USA) by plotting the percentage of viable cells as a function of the compound concentration.

2.9. Protein Extraction from Cells. To perform a twodimensional (2D) difference gel electrophoresis (DIGE) protein expression analysis, the total cellular proteins of binasetreated A549 cells $(100 \mu \mathrm{g} / \mathrm{ml})$ were extracted after $12 \mathrm{~h}$ of incubation in 6-well plates (in triplicate). Binase nontreated cells were taken as control. After removal of the cell culture media, the cell monolayers were washed twice with $\mathrm{PBS}^{++}$, scratched off, and collected in $1 \mathrm{ml}$ PBS. The cells were then pelleted by centrifugation for $30 \mathrm{sec}$ at $13000 \mathrm{~g}$ and $4^{\circ} \mathrm{C}$. The supernatant was discarded and cell pellets were lysed on ice using lysis buffer (TLB: $25 \mathrm{mM}$ Tris, $\mathrm{pH} 8.0$; $137 \mathrm{mM} \mathrm{NaCl} ; 10 \%$ glycerol; $0.1 \%$ sodium dodecyl sulphate; $0.5 \%$ sodium deoxycholate; $1 \%$ NP- $40 ; 2$ mM EDTA, $\mathrm{pH}$ 8.0; $0.2 \mathrm{mM}$ Pefablock; $5 \mu \mathrm{g} / \mathrm{ml}$ aprotinin; $5 \mu \mathrm{g} / \mathrm{ml}$ leupeptin; $1 \mathrm{mM}$ Na-vanadate; and $5 \mathrm{mM}$ benzamidine). After adding the lysis buffer, the cells were incubated for $10 \mathrm{~min}$ on ice and successively centrifuged for $30 \mathrm{~min}$ at $13000 \mathrm{~g}$ with $4^{\circ} \mathrm{C}$ and supernatants were collected. The protein concentration of each sample was determined according to the manufacturer's instruction using Bradford Assay Kit (Bio-Rad, USA).

2.10. Cyanine Dye Labeling of Protein Samples. Total cellular proteins $(100 \mu \mathrm{g})$ from binase nontreated (control) and binase-treated samples were labeled with green (Cy3) and red (Cy5) cyanine dyes at a concentration of 800 pmol dye $/ 100 \mu \mathrm{l}$ of proteins, respectively. The dye and protein mix were incubated on ice for $1 \mathrm{~h}$ in the dark at RT. The labeling reaction was terminated by incubating with $10 \mathrm{mM}$ lysine for $10 \mathrm{~min}$. The labeled protein was mixed and used for isoelectric focusing (IEF).

2.11. 2D Difference Gel Electrophoresis. The isoelectric $\mathrm{pH}$ gradient (IPG) tube gel was prepared using $8 \mathrm{M}$ urea; $4 \%$ acrylamide; $2.4 \%$ ampholytes; $2.4 \%$ CHAPS; and NP40 according to Protean IEF Cell (Bio-Rad, USA) manufacturer's instructions. $100 \mu \mathrm{g}$ of each labeled protein mix from control and test samples was combined in a $50 \mu \mathrm{l}$ standard buffer (8 M urea; $4 \%$ CHAPS and NP-40; $10 \mathrm{mM}$ Tris- $\mathrm{HCl}, \mathrm{pH}$ 8.5) containing $2 \%$ DTT (dithiothreitol) and added onto the prepared IEF gel in a tube. The first-dimensional isoelectric focusing was carried out on a PROTEAN II xi Cell (Bio-Rad, USA) chamber at RT using the following program: $100 \mathrm{~V}$ for $1 \mathrm{~h}, 200 \mathrm{~V}$ for $1 \mathrm{~h}$, a gradient of $200 \mathrm{~V}-700 \mathrm{~V}$ for $6 \mathrm{~h}, 700 \mathrm{~V}$ for $5 \mathrm{~h}, 900 \mathrm{~V}$ for $1.5 \mathrm{~h}$, and $1000 \mathrm{~V}$ for $1 \mathrm{~h}$.

The $9-16 \%$ polyacrylamide gradient gel for twodimensional gel electrophoresis was prepared according to Protean IEF Cell (Bio-Rad, USA) manufacturer protocol. The IEF gel was equilibrated for $15 \mathrm{~min}$ in SDS-PAAG equilibration buffer (6 M urea; $0.375 \mathrm{M}$ Tris- $\mathrm{HCl}, \mathrm{pH} 8.8$; $2 \%$ SDS; $20 \%$ glycerol; $2 \%(\mathrm{w} / \mathrm{v}) \mathrm{DTT}$ ) for $15 \mathrm{~min}$. The IEF gel was carefully placed on top of $9-16 \%$ SDS-PAAG with $400 \mathrm{ml}$ upper electrolyte $(20 \mathrm{mM} \mathrm{NaOH})$ on glass plate. 2 liters of lower electrolyte contained $20 \mathrm{mM}$ of $\mathrm{H}_{3} \mathrm{PO}_{4}$. The electrophoresis was carried out using the following program:
$20 \mathrm{~mA}$ for $20 \mathrm{~min}, 40 \mathrm{~mA}$ for $2 \mathrm{~h}$, and $35 \mathrm{~mA}$ for $3 \mathrm{~h}$. The proteins separated on gels covering the $15-150 \mathrm{kDa}$ range. A Typhoon FLA 9500 Imager (GE Healthcare, UK) was used to visualize protein spot on the gels. The excitation and emission wavelength combinations of $532 \mathrm{~nm}$ and $635 \mathrm{~nm}$ were used to capture the images of protein labeled with Cy3 and Cy5, respectively. The spot detection matching was carried out by using ImageQuant TL software (GE Healthcare, UK).

2.12. Plasmids and Primers. For the in vitro reconstitution of viral ribonucleoprotein (vRNP) complex, four plasmids pHW-PB1-Hamburg, pHW-PB2-Hamburg, pHW-PAHamburg, and pHW-NP-Hamburg generating the mRNAs of polymerases and NP segments of H1N1pdm virus together with pPoll-GFP-RT generating a vRNA-like Poll-transcript encoding the green fluorescent protein (GFP) were used. GFP, a reporter protein in negative-sense, are flanked by the $3^{\prime}$ - and $5^{\prime}$-noncoding region of the NS RNA segment of influenza A/WSN/33 virus [2] placed between a truncated human RNA polymerase I promotor (POLI) and hepatitis delta virus ribozyme (R). The expressed subunits of the viral polymerases and nucleoprotein replicated and transcribed the influenza virus-like RNA expressed by pPOLI-GFP-RT into mRNA.

To perform the real-time RT-PCR the primer pairs (Actin_SYBR_F: 5'-AGG CAC CAG GGC GTG AT-3'; Actin_SYBR_R: $5^{\prime}$-GCC CAC ATA GGA ATC CTT CTG AC- $3^{\prime}$ and GAPDH_SYBR_F: $5^{\prime}$-CCA GGT GGT CTC CTC TGA CTT C-3'; GAPDH_SYBR_R: $5^{\prime}$-CAA AGT GGT CGT TGA GGG CAA TG-3') were used to amplify the cellular ACTB (beta-actin) and GAPDH (glyceraldehyde-3phosphate dehydrogenase) genes, respectively. The H1N1pdm viral NP mRNA specific primer pairs (HH_SYBR_F: $5^{\prime}$-GGC CAT AAG GAC CAG GAG TG-3'; HH_SYBR_R: $5^{\prime}-\mathrm{CCG}$ CTG AAT GCT GCC ATA AC- $3^{\prime}$ ) were used to identify the binase effect on influenza A viral RNA using real-time RTPCR.

2.13. RNA Extraction and cDNA Preparation. To identify the binase action on the cellular and viral mRNA expression levels in A549-infected cells with H1N1pdm, binase-treated/infected, binase-treated/noninfected, noninfected, and nontreated A549 cells were kept for $12 \mathrm{~h}$ in 6-well plate (in triplicate). After washing with $\mathrm{PBS}^{++}$, the scratched cells were collected in PBS and immediately counted. $10^{6}$ cells from each sample were used for RNA extraction and cDNA preparation. The cells from each sample were lysed with RLT buffer (Qiagen, Germany). Total RNA was purified using a RNeasy mini Kit (Qiagen, Germany) according to recommended protocol. The total RNAs of each sample were eluted from each filter using the same volume of elution buffer. Equal volumes of total RNA were used to amplify A549 cellular mRNA of ACTB, mRNA of GAPDH, and H1N1pdm viral NP mRNA genes cDNA using MMLV RT Kit (Evrogen, Russia). In brief, $0.5-2 \mu \mathrm{g}$ of each total RNA in equal volume of each eluted sample was mixed with $20 \mu \mathrm{M}$ specific reverse primer, preincubated for $2 \mathrm{~min}$ at $70^{\circ} \mathrm{C}$, and then immediately snap-cooled on ice. The reverse transcription was performed 
in $20 \mu \mathrm{l}$ solution containing preprepared RNA and primer mix, $100 \mathrm{U}$ of MMLV reverse transcriptase, $1 \mathrm{mM}$ of $\mathrm{dNTP}$ mix, $2 \mathrm{mM}$ of DTT, 1x buffer of MMLV RT Kit (Evrogen, Russia), and $1 \mathrm{U}$ RiboLock RNase Inhibitor (Thermo Fisher Scientific, USA). The RT-PCR was performed for $60 \mathrm{~min}$ at $42^{\circ} \mathrm{C}$. The cDNA of each sample were diluted 1:10 using RNase free water (Thermo Fisher Scientific, USA) and used as a template for real-time PCR.

2.14. Real-Time PCR. To quantify the cellular and viral mRNA in A549 cells using qPCRmix-HS SYBR Kit (Evrogen, Russia), the $4 \mu \mathrm{l}$ of each cDNA (1-100 ng to each reaction) (see Section 2.13), $0.4 \mu \mathrm{M}$ of each (forward and reverse) primers, and 1x qPCRmix-HS SYBR (Evrogen, Russia) were mixed in a LightCycler 480 Multiwell Plate 96 (Roche Diagnostics, Switzerland) on ice in the dark and covered by LightCycler 480 Sealing Foil. Thermal cycling was done on a LightCycler 480 (Roche Diagnostics, Switzerland) system under the following conditions: $10 \mathrm{~min}$ at $95^{\circ} \mathrm{C} ; 40$ cycles of $15 \mathrm{sec}$ at $95^{\circ} \mathrm{C}$; $30 \mathrm{sec}$ at $60^{\circ} \mathrm{C}$; and $30 \mathrm{sec}$ at $30^{\circ} \mathrm{C}$. The quantification and data analysis was performed using the LightCycler 480 Service Software (Roche Diagnostics, Switzerland). For identification of binase action on cellular mRNA or H1N1pdm viral NP mRNA accumulation according to the relative fold-difference of expression levels (relative changes in gene expression from real-time quantitative PCR experiments) using internal control, mRNA expression data of a reference GAPDH gene was used to correct the control/calibrator (binase nontreated) and test/experimental (binase-treated) samples data. The $\Delta \mathrm{Ct}$ value of the calibrator from influenza virus-infected and binase nontreated cells $\left(\mathrm{Ct}_{\text {target }}(\mathrm{Ct}\right.$ value obtained using H1N1pdm viral NP mRNA specific primers in A549 cells) - $\mathrm{Ct}_{\text {reference }}$ (Ct value obtained using GAPDH mRNA primers in A549 cells)) and $\Delta \mathrm{Ct}$ value of the test from influenza virusinfected and binase-treated cells $\left(\mathrm{Ct}_{\text {target }}-\mathrm{Ct}_{\text {reference }}\right)$ were calculated. The fold change was calculated using $2^{-\Delta \Delta \mathrm{Ct}}$ value, where $\Delta \Delta \mathrm{Ct}=\Delta \mathrm{Ct}$, test $-\Delta \mathrm{Ct}$, calibrator.

2.15. Transfection. To investigate the effect of binase on the gene expression activity of H1N1pdm virus, $1 \mu \mathrm{g}$ of every five plasmids (see Section 2.12) encoding viral ribonucleoprotein complex together with pPOLI-GFP-RT was cotransfected into A549 cells as previously described with minor modifications (in triplicate) $[15,16]$. Briefly, the transfection mixture consisting of $180 \mu \mathrm{l}$ "Opti-MEM" (Thermo Fisher Scientific, USA) and total of $5 \mu \mathrm{g}$ of plasmid DNA along with $12 \mu \mathrm{l}$ “TransIT-2020" (Mirus Bio, USA) was incubated for $45 \mathrm{~min}$ at RT. Then, the mixture was diluted to $1 \mathrm{ml}$ using "Opti-MEM" and transferred to 80-90\% confluent A549 cell monolayer (grown in 6-well plate) to allow transfection. The cells were then kept for $12 \mathrm{~h}$ at $37^{\circ} \mathrm{C}$ in $5 \% \mathrm{CO}_{2}$ incubator. The transfection medium was replaced with $2 \mathrm{ml}$ of OptiMEM containing $0.2 \% \mathrm{BA}$ and $\mathrm{P} / \mathrm{S}$ with binase $(10 \mu \mathrm{g} / \mathrm{ml})$ or without binase. After $36 \mathrm{~h}$, the GFP expression was visualized and counted by Axiovert 35 inverted fluorescent microscope (Zeiss, Germany).

2.16. Statistical Analysis. Statistical tests and graphical data presentation were performed using GraphPad Prism 5 Software (GraphPad Software, Inc., USA) and MS Excel 2010
(Microsoft, USA). All data are presented as the mean \pm standard deviation of the mean (SD). The significance between two groups was determined via "Student $t$-test." A significant difference was considered to be a $P$ value of $<0.05$.

2.17. Biosafety. All experiments involving influenza A (H1N1pdm) and rhinovirus serotype 1A (HRV1A) were performed using biosafety level 2 containment laboratory approved for such use by the local authorities (RP, Giessen, Germany).

\section{Results and Discussion}

In the present work, we have studied the effect of bacterial ribonuclease binase on infectious titer of negative-sense single stranded RNA influenza A (H1N1pdm) virus after its single-cycle replication in A549 cell culture ( $12 \mathrm{~h}$ p.i.). In contradistinction to the previous report on the maximum anti-influenza effect of binase after multicycle virus replication [13], here, we have focused on the time period of $12 \mathrm{~h}$ p.i. to study virus gene expression at the moment of first round progeny virions formation. It was found that $45 \mathrm{~min}$ preincubation of binase at concentration of $10 \mu \mathrm{g} / \mathrm{ml}$ with virus led to decrease in infectious virus titer by 5 -fold at an MOI of 0.1 (Figure 1(a)). At an MOI of 0.01 the reduction of virus titer after binase treatment was more significant (8fold). The higher antiviral effectiveness of binase on lower virus titer suggests the possible administration of binase at the early phase of virus infection or for prophylaxis.

The catalytic activity of binase $(100 \mu \mathrm{g} / \mathrm{ml})$ in A549 cell culture media decreased to $50 \%$ after $48 \mathrm{~h}$ incubation (Figure 1(b)) that corresponded to the data obtained earlier for $1 \mu \mathrm{g} / \mathrm{ml}$ binase [13]. Binase is a thermo- and $\mathrm{pH}$-stable agent, which can be used in vivo retaining its activity. The $49 \%$ reduction of binase activity in the cell culture fluid can be explained by internalization of the enzyme to the A549 cells. Binase internalization to A549 cell cytoplasm and nucleus was previously illustrated by immunofluorescence methods [17]. Possible inhibition of catalytic activity and partial degradation of binase by extracellular proteases are not excluded though. Thus, binase acts as the antiviral agent under wide range of concentrations after short and long period of incubation. Moreover, the additional binase administration is not needed during $48 \mathrm{~h}$.

It is known that binase at concentrations up to $100 \mu \mathrm{g} / \mathrm{ml}$ is not toxic towards A549 cells [13, 17] while inhibiting H1N1pdm virus propagation $[8,13]$. We have shown here that a concentration of binase of $100 \mu \mathrm{g} / \mathrm{ml}$ without preincubation of the virus (at an MOI of 1) with binase reduced the infectious titer in A549 cell culture by $40 \%$ after a single replication round (Figure $1(\mathrm{c})$ ). Therefore, binase seems to be able to act intracellularly on viruses before they exit the cells. This raises a question regarding antiviral targets of binase in the virus-infected cells. We performed a 2D-DIGE of binasetreated and nontreated cells. It was determined that binase at $100 \mu \mathrm{g} / \mathrm{ml}$ does not alter the spectrum of A549 cellular proteins (Figure 2(a)). Moreover, the expression of cellular housekeeping genes, measured by mRNA levels of genes 


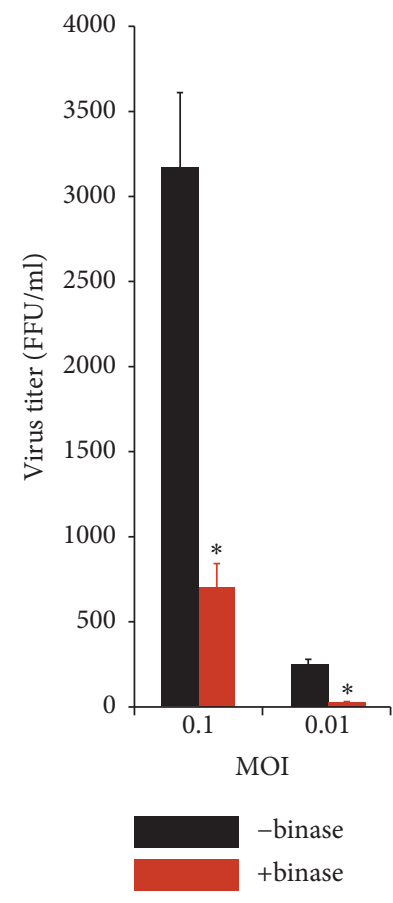

(a)

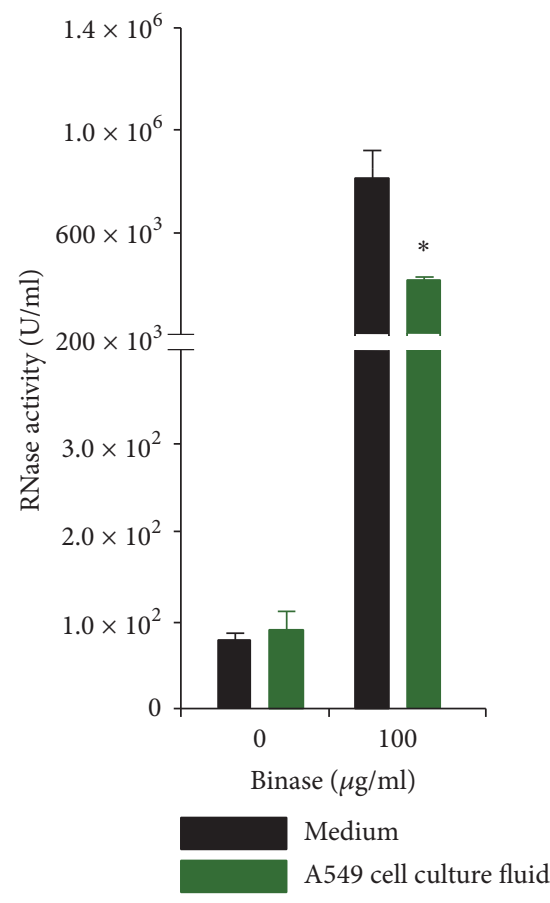

(b)

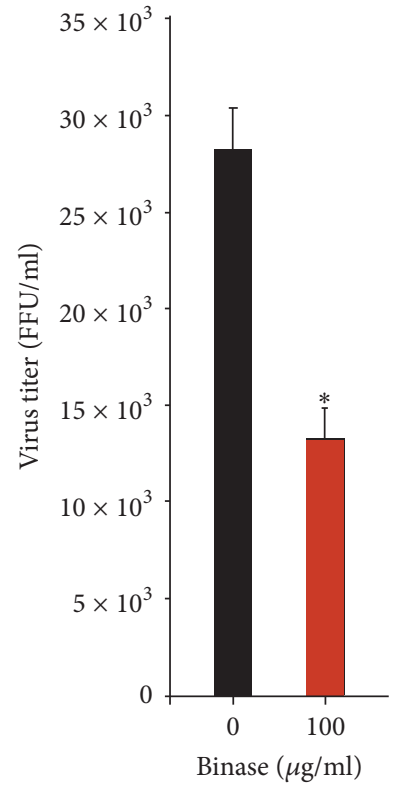

(c)

FIGURE 1: (a) Decrease of H1N1pdm virus titer in A549 cells infected by virus at an MOI of 0.01 and 0.1 which was preincubated with $10 \mu \mathrm{g} / \mathrm{ml}$ binase for $45 \mathrm{~min}$ prior to cell infection; (b) binase catalytic activity in cell-free medium and A549 cell culture medium after $48 \mathrm{~h}$ incubation; (c) virus titer after $12 \mathrm{~h}$ incubation of A549 cells treated by $100 \mu \mathrm{g} / \mathrm{ml}$ binase and infected by H1N1pdm virus at an MOI of 1 . FFU/ml were calculated using supernatant after single-cycle replication of virus. Statistical significance was calculated using GraphPad Prism 5.0 Software and assessed by Student's $t$-test: ${ }^{*} P<0.001$.

encoding structural protein $\mathrm{ACTB}$ and metabolic protein GAPDH, was not changed upon treatment of A549 cells with $100 \mu \mathrm{g} / \mathrm{ml}$ of binase followed by $12 \mathrm{~h}$ incubation (Figure 2(b)). At the same time, binase reduced H1Nlpdm viral NP mRNA accumulation in the A549 cells infected with virus at an MOI of 1 (Figure 2(c)), probably, reflecting the specific reduction of viral RNA. Expression of the gene was 20\% lower in binase-treated virus-infected cells than in the virus-infected binase nontreated cells. These results support the idea of an inhibitory effect of binase on virus replication (Figure 1(c)).

To gain a more detailed evidence of binase effect on H1N1pdm viral gene expression in A549 cells we used a plasmid based reverse genetic system containing a set of plasmids encoding PB1, PB2, PA, and NP genes of H1N1pdm viral RNP complex and an influenza virus-like RNA encoding a GFP reporter protein (see Sections 2.12 and 2.15). GFP fluorescence is detectable only if plasmid-encoded genes for the RNP complex and the virus-like RNA are expressed. It was determined that binase reduced the viral RNA expression by 4.4 times indicating the binase inhibition of the expression of viral genes (Figures 3(a) and 3(b)). Therefore, a target of binase antiviral action could be viral mRNA. Its degradation prevents synthesis of viral proteins.

In Figure 4, we have shown a scheme reflecting different possible mechanisms of a binase effect on influenza A viral functional ribonucleoprotein (RNP) complex gene expression using a vRNA-like Poll-transcript encoding a reporter gene (GFP) step by step starting from internalization of binase (steps A and B) to the step of blocking of viral translation (steps C, D). Steps depicting production of reporter mRNA (7-8) and transcription of viral RNP mRNA (4-5) can be inhibited by binase.

Based on the conducted experiments, we can conclude that binase acts on synthesized positive-sense mRNA; however, we do not rule out that binase would digest negativesense vRNA of H1Nlpdm virus or its cRNA. With respect to vRNA it seems less possible, because vRNA is protected by NP proteins and, moreover, its degradation would result in complete elimination of the virus from the cell culture. To confirm the ability of binase to degrade positive-sense RNA of virus, which ignores the internalization and localization in nuclei in order to serve as a template during translation of viral proteins, we used a different system: HeLa cells were infected by positive-sense RNA-containing HRV1A virus. In HeLa cells HRV1A virus is easily propagated; it replicates in HeLa cells to high titers. We show binase is nontoxic for HeLa cells in concentrations under $100 \mu \mathrm{g} / \mathrm{ml}$ (Figure 5(a)). It reduced the titer of HRV1A virus by 3 times at $100 \mu \mathrm{g} / \mathrm{ml}$ (Figure 5(b)). The results confirmed the possibility of binase to degrade viral positive-sense RNA without internalization 


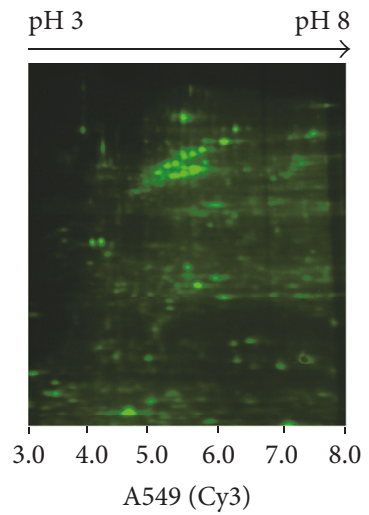

(i)

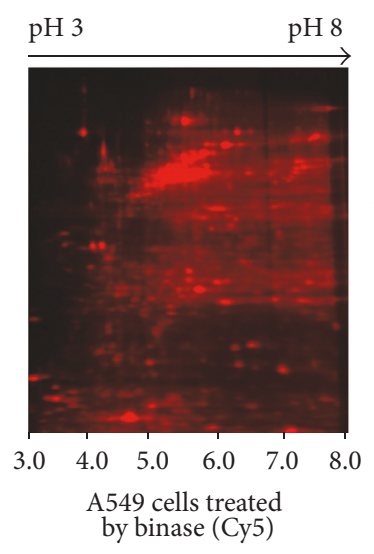

(ii)

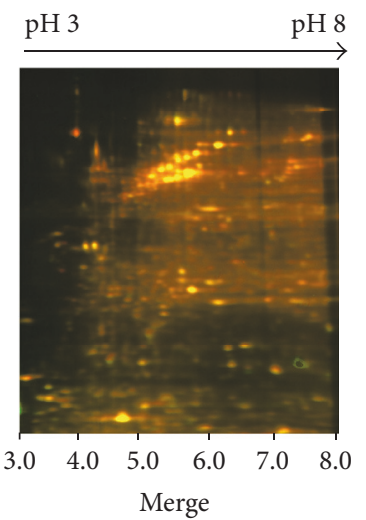

(iii)

(a)

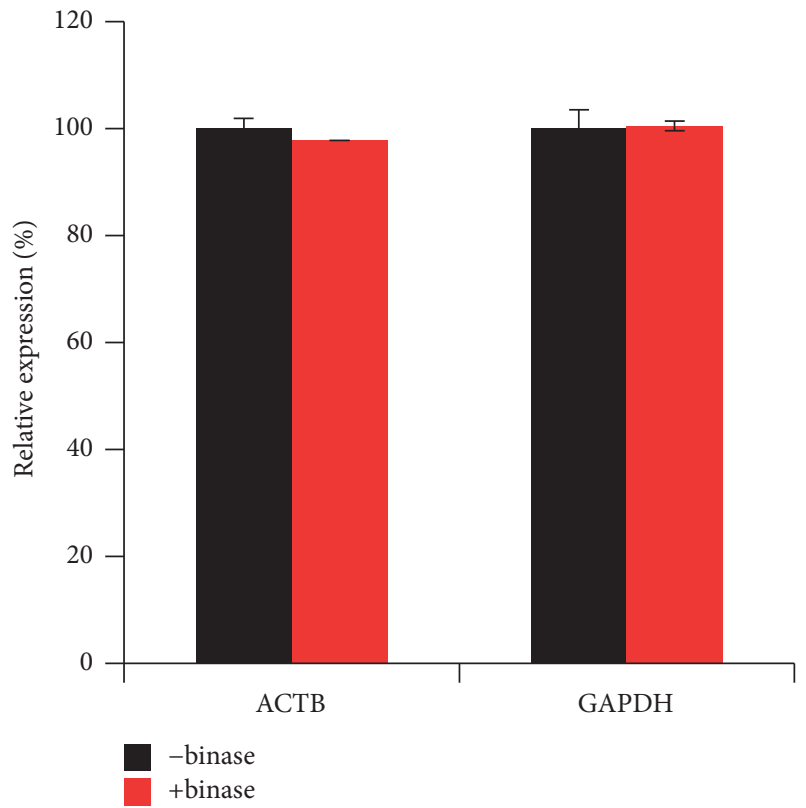

(b)

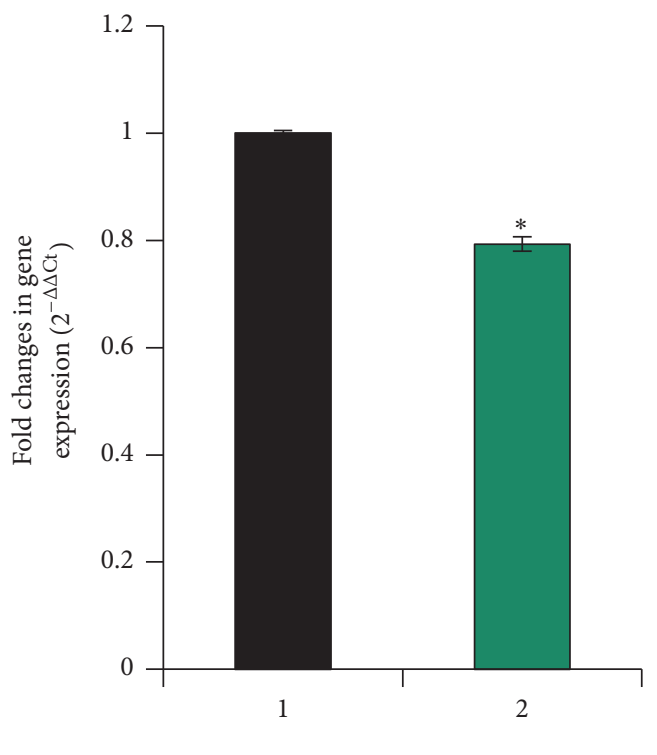

(c)

FIGURE 2: (a) Influence of $100 \mu \mathrm{g} / \mathrm{ml}$ binase at $12 \mathrm{~h}$ p.i. on proteome of A549 cells. Two-dimensional difference gel electrophoresis (2D-DIGE) of proteins isolated from nontreated ((i), green labeling by Cy3) and binase-treated cells ((ii), red labeling by Cy5); (iii) merged image, unchanged protein spots appeared yellow. High resolution 2D-DIGE images were generated using Typhoon FLA 9500 Imager; samples were separated using narrow range of IEF tube gel, $\mathrm{pH} 3-8$; gels cover 15-150 kDa range. (b) Real-time RT-PCR analysis of mRNA transcripts of housekeeping genes (beta-actin, ACTB; glyceraldehyde-3-phosphate dehydrogenase, GAPDH) in noninfected, binase-treated (100 $\mu \mathrm{g} / \mathrm{ml}$, $12 \mathrm{~h}$ ), and nontreated A549 cells. (c) H1N1pdm viral NP mRNA in infected nontreated A549 cells (1) and treated by $100 \mu \mathrm{g} / \mathrm{ml}$ binase after $12 \mathrm{~h}$ (2). GAPDH mRNA was used as a loading control to normalize viral mRNA accumulation. $10^{6}$ cells from each sample were used to measure mRNA levels using Roche Light Cycler 480 system and target-specific primers. Statistical significance was calculated using GraphPad Prism 5.0 Software and assessed by Student's $t$-test: ${ }^{*} P<0.01$. 


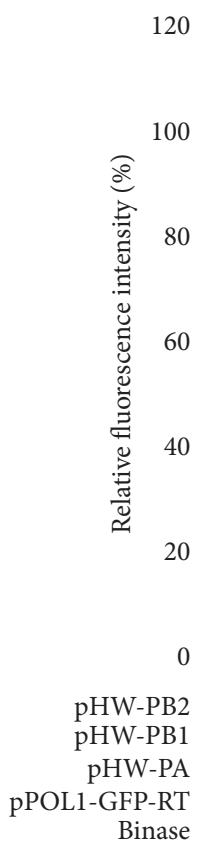

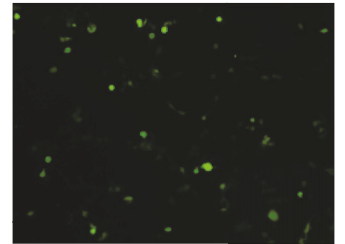

(i)

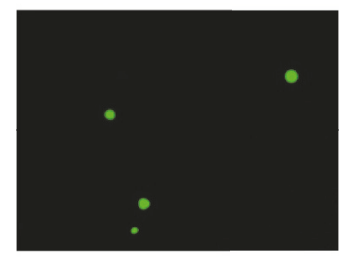

(ii)

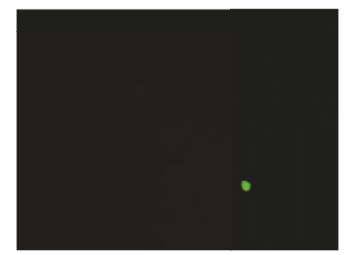

(iii)

(b)

Figure 3: Effect of binase on functional H1N1pdm viral RNP polymerase complex formation in A549 cells transfected by plasmids (pHW) encoding vRNP subunits (PB1, PB2, and PA) and NP of H1N1pdm virus together with vRNA-like transcript pPOLI-GFP-RT encoding GFP. Decrease of GFP expression in the cells treated by binase (a) and visualization of this effect using Axiovert 35 inverted fluorescent microscope (b). (i) A549 cells carrying PAM 503 plasmid as GFP expression control; (ii) A549 cells without binase treatment; (iii) A549 cells treated by $10 \mu \mathrm{g} / \mathrm{ml}$ binase after transfections. Statistical significance was calculated using GraphPad Prism 5.0 Software and assessed by Student's $t$-test: ${ }^{*} P<0.001$.

into the nucleus. Thus, regardless of the negative- or positivesense genome of single stranded RNA viruses, binase might be able to cleave viral RNA catalytically and thereby inhibit the synthesis of the viral proteins. This property of the bacterial enzyme uncovers the promising aspects of its application as a new antiviral agent.

To replicate successfully, viruses protect their genomic material from degradation by the host cell. RNA viruses must contend with numerous destabilizing host cell processes including mRNA decay pathways and viral RNA degradation resulting from the antiviral response [18]. However, viruses do not possess specific defense system against bacterial RNases applied exogenously, and viral mRNA remains an important target for antiviral drug discovery.

To impair viral RNA transcription, different strategies have been used. For example, siRNA duplexes directed against the Rift Valley fever virus (RVFV) nucleoprotein can effectively inhibit RVFV replication in human (MRC5 cells) and African green monkey cells (Vero E6 cells). It was shown that pretreatment of cells with the nucleoprotein-specific siRNAs markedly reduces the virus titer [19]. Protein-protein interactions of PB1-PB2 subunits play pivotal roles in assembling the functional polymerase complex, which is essential for the replication and transcription of influenza virus
RNA. Novel small molecule compounds which inhibited the interaction of RNA-dependent RNA polymerase subunits were identified. Recent efforts of discovery of antiviral drugs targeting RNA have provided drug-like small molecules that inhibit viral replication and include inhibitors of human immunodeficiency virus (HIV), hepatitis C virus (HCV), severe acute respiratory syndrome coronavirus (SARS CoV), and influenza A virus [20]. Highly conserved noncoding RNA (ncRNA) elements in viral genomes and transcripts offer new opportunities to expand the repertoire of drug targets for the development of anti-infective therapy. Viruses for which targeting ncRNA components in the genome or transcripts may be promising include insect-borne flaviviruses (Dengue, Zika, and West Nile) and filoviruses (Ebola and Marburg) [21].

According to our data, both negative-sense and positivesense RNA-containing viruses can be targeted by binase. The +ssRNA transcript of influenza virus is used as mRNA for the synthesis of structural proteins; +ssRNA of rhinovirus is used both as mRNA and as the packaged genome. The rhinovirus +ssRNA does not need to be transported into the nucleus; the influenza +ssRNA is also located in the cytoplasm. Cytoplasmic allocation of +ssRNAs facilitates their targeting by binase. We have shown previously that 


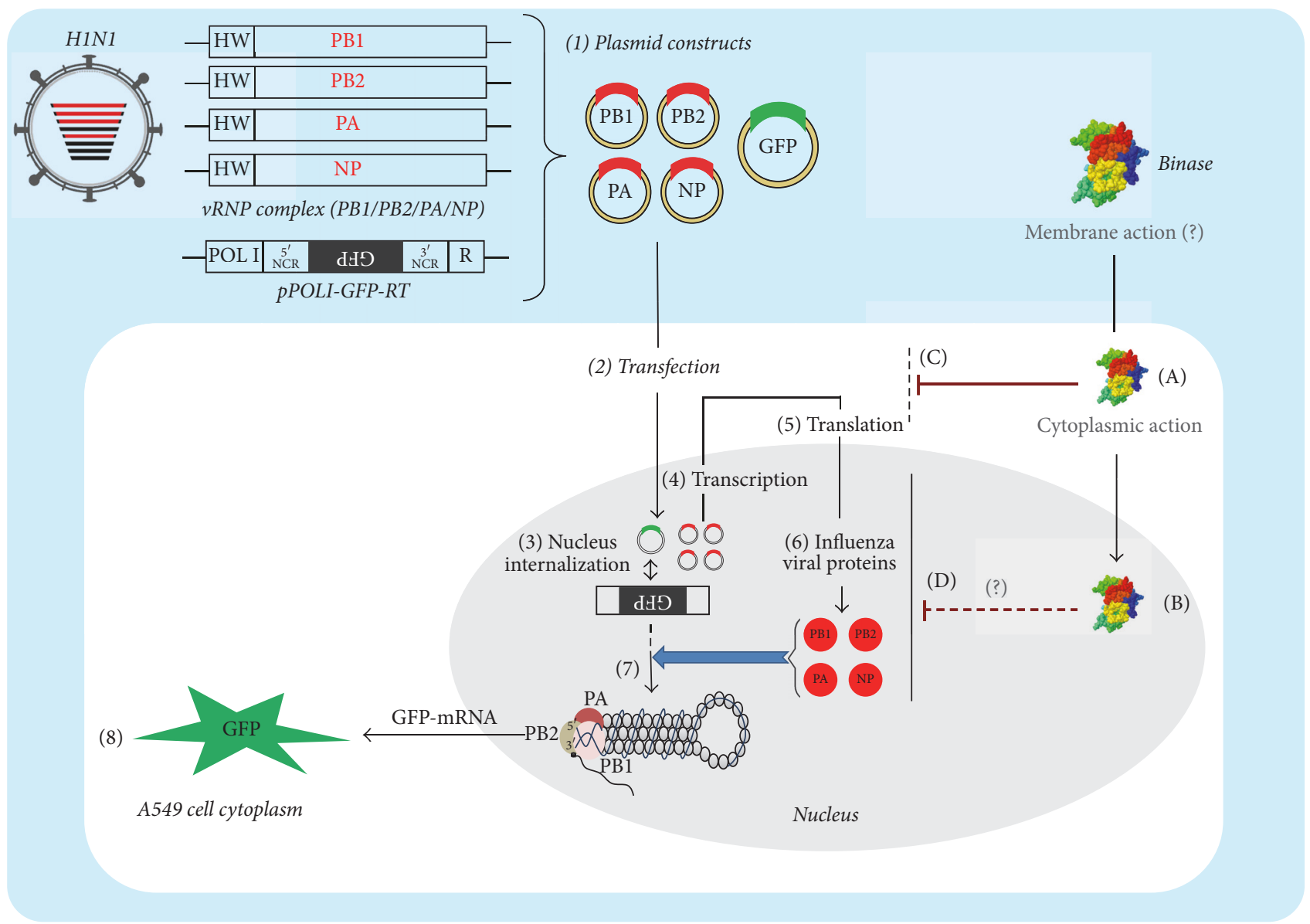

FIGURE 4: Hypothetic scheme of binase influence on functional viral RNP polymerase complex formation monitored by GFP fluorescence in the cells using the influenza A virus mini genome system. For the in vitro reconstitution of viral ribonucleoprotein complex (vRNP), plasmids pHW-PB1-Hamburg, pHW-PB2-Hamburg, pHW-PA-Hamburg, and pHW-NP-Hamburg were used. They carry genes for generating the mRNAs of polymerases and NP segments of H1N1pdm virus. These plasmids were transfected into A549 cells along with pPOLI-GFP-RT plasmid, which generates a vRNA-like POLI-transcript encoding the green fluorescent protein. GFP gene in a latter construct is encoded in negative-sense and flanked by the $3^{\prime}$ - and $5^{\prime}$-noncoding region of the NS RNA segment of influenza A/WSN/33 virus [2] placed between a truncated human RNA polymerase I promotor (POLI) and hepatitis delta virus ribozyme (R). The expressed subunits of the viral polymerases and nucleoprotein replicate and transcribe the influenza virus-like RNA expressed by pPOLI-GFP-RT into GFP mRNA, resulting in the detection of GFP activity in transfected cells. The described steps are labeled as follows: (1) plasmid constructs encoding vRNP subunits and GFP as a reporter protein, (2-3) transfection and internalization of plasmids into nucleus of A549 cells, (4-6) expression of viral polymerase complex, (7) maturation of GFP transcript by viral polymerase complex, and (8) GFP signaling. Possible binase actions are represented in the steps: (A) binase internalization into cytoplasm, (B) binase internalization into nucleus, (C) and (D) inhibitory effect of binase on the expression of influenza A virus mini genome system in cytoplasm and nucleus, respectively.

massive internalization of binase into nucleus had already started after $3 \mathrm{~h}$ of binase incubation with A549 cells [17]. Therefore, we can propose that binase targets -ssRNA too.

\section{Conclusion}

We found that binase at nontoxic concentrations to eukaryotic cells does not alter the cellular protein production or mRNA expression but affects viral RNA production. Binase exerts its antiviral effect both against positive- and negativesense RNA viruses suggesting binase as a promising antiviral agent against different viruses.

\author{
Abbreviations \\ RNase: Ribonuclease \\ RI: $\quad$ RNase inhibitor protein \\ ACTB: $\quad \beta$-Actin \\ GAPDH: Glyceraldehyde-3-phosphate dehydrogenase \\ RNP: Ribonucleoprotein \\ GFP: $\quad$ Green fluorescent protein \\ MOI: Multiplicity of infection \\ FFU: $\quad$ Focus forming units \\ p.i.: Postinfection \\ IEF: Isoelectric focusing \\ +ssRNA: Positive-sense single stranded RNA \\ -ssRNA: Negative-sense single stranded RNA.
}




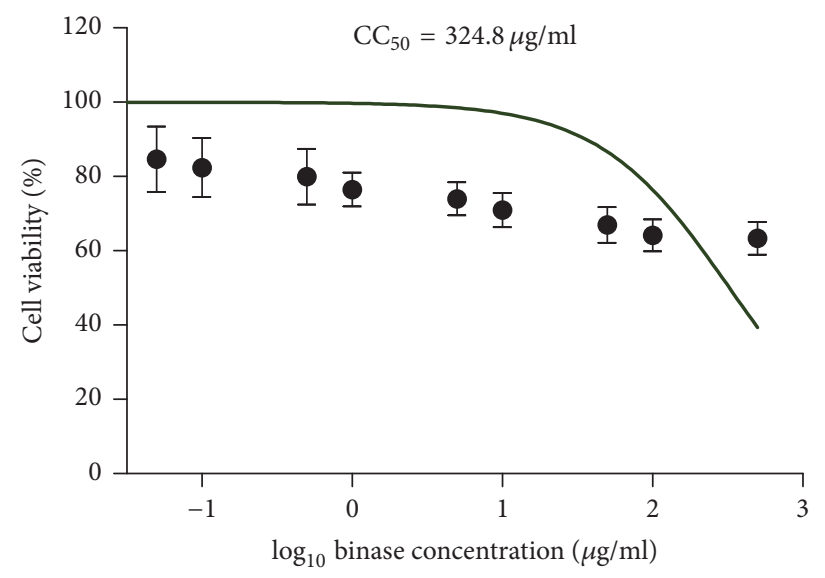

(a)

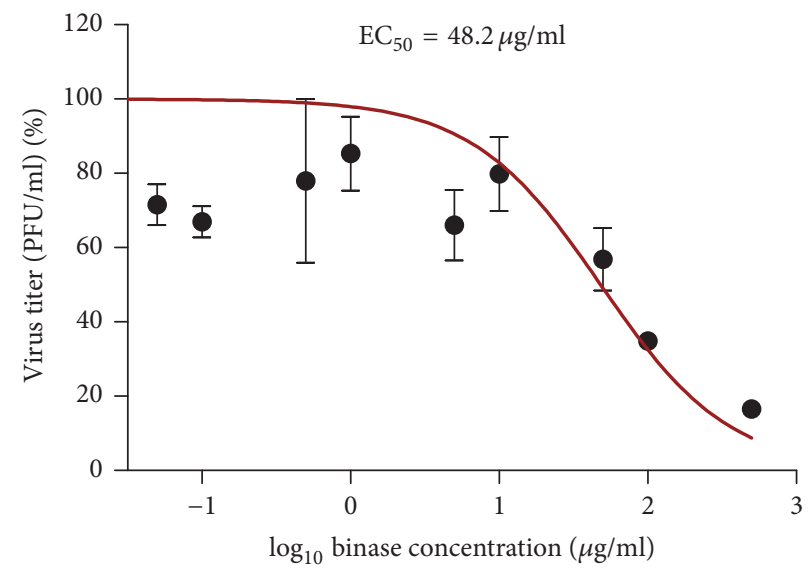

(b)

FiguRE 5: Viability of HeLa cells treated by binase ( $24 \mathrm{~h}$ ) (a) and the influence of binase on HRV1A virus titer after $24 \mathrm{~h}$ incubation of HeLa cells with different concentrations of the RNase. $\mathrm{CC}_{50}$ and $\mathrm{EC}_{50}$ are the binase concentration, which induces $50 \%$ cell death and $50 \%$ reduction of virus titer, respectively. $1 \mu \mathrm{g} / \mu \mathrm{L}$ of binase corresponds to $82 \mu \mathrm{M}$. The $R$-squared value and cytotoxic and effective concentrations were calculated using GraphPad Prism 5.0 Software.

\section{Disclosure}

The funders had no role in study design, data collection and analysis, decision to publish, or preparation of the manuscript.

\section{Conflicts of Interest}

The authors declare that there are no conflicts of interest regarding the publication of this article.

\section{Acknowledgments}

The work was supported by the KFU, Russia, and JLU Giessen, Germany, partnership program and the program for competitive growth of KFU. This work was also supported by the Russian Science Foundation Grant no. 14-14-00522, by the program "Research Stays for University Academics and Scientists" by the German Academic Exchange Service (DAAD), and in part by the German Centre for Infection Research (DZIF), partner site Giessen, Germany (TTU Emerging Infections to SP). Equipment of the Institute of Medical Virology JLU, Giessen, Germany, and the Interdisciplinary Center for Collective Use (ID RFMEFI59414X0003) sponsored by Ministry of Education and Science of the Russian Federation was used.

\section{References}

[1] N. Glanville and S. L. Johnston, "Challenges in developing a cross-serotype rhinovirus vaccine," Current Opinion in Virology, vol. 11, pp. 83-88, 2015.

[2] S. Pleschka, R. Jaskunas, O. G. Engelhardt, T. Zürcher, P. Palese, and A. Garcia-Sastre, "A plasmid-based reverse genetics system for influenza A virus," Journal of Virology, vol. 70, no. 6, pp. 4188-4192, 1996.
[3] R. R. Razonable, "Antiviral drugs for viruses other than human immunodeficiency virus," Mayo Clinic Proceedings, vol. 86, no. 10, pp. 1009-1026, 2011.

[4] S. Milanoi, J. R. Ongus, G. Gachara, R. Coldren, and W. Bulimo, "Serotype and genetic diversity of human rhinovirus strains that circulated in Kenya in 2008," Influenza and Other Respiratory Viruses, vol. 10, no. 3, pp. 185-191, 2016.

[5] W. Olszewska, M. Zambon, and P. J. M. Openshaw, "Development of vaccines against common colds," British Medical Bulletin, vol. 62, no. 1, pp. 99-111, 2002.

[6] B. N. Glukhov, A. P. Jerusalimsky, V. M. Canter, and R. I. Salganik, "Ribonuclease treatment of tick-borne encephalitis," Archives of Neurology, vol. 33, no. 9, pp. 598-603, 1976.

[7] V. Ulyanova, R. Shah Mahmud, E. Dudkina, V. Vershinina, E. Domann, and O. Ilinskaya, "Phylogenetic distribution of extracellular guanyl-preferring ribonucleases renews taxonomic status of two Bacillus strains," Journal of General and Applied Microbiology, vol. 62, no. 4, pp. 181-188, 2016.

[8] O. N. Ilinskaya and R. Shah Mahmud, "Ribonucleases as antiviral agents," Molecular Biology, vol. 48, no. 5, pp. 615-623, 2014.

[9] R. Shah Mahmud, M. Efimova, A. Mostafa, V. Ulyanova, and O. Ilinskaya, "Antiviral activity of bacterial extracellular ribonuclease against single-, double-stranded RNA and DNA containing viruses in cell cultures," BioNanoScience, vol. 6, no. 4, pp. 561-563, 2016.

[10] M. A. Efimova, R. Shah Mahmud, P. V. Zelenikhin, M. I. Sabirova, A. I. Kolpakov, and O. N. Ilinskaya, "Exogenous Bacillus pumilus RNase (binase) suppresses the reproduction of reovirus serotype 1," Molecular Biology, vol. 51, no. 1, pp. 96-101, 2017.

[11] C. Müller, V. Ulyanova, O. Ilinskaya, S. Pleschka, and R. Shah Mahmud, "A novel antiviral strategy against MERS-CoV and $\mathrm{HCoV}-229 \mathrm{E}$ using binase to target viral genome replication," BioNanoScience, vol. 7, no. 3, 2017.

[12] E. Dudkina, V. Ulyanova, R. Shah Mahmud et al., "Threestep procedure for preparation of pure Bacillus altitudinis ribonuclease," FEBS Open Bio, vol. 6, no. 1, pp. 24-32, 2016. 
[13] R. Shah Mahmud and O. N. Ilinskaya, "Antiviral activity of binase against the pandemic influenza A (H1N1) virus," Acta Naturae, vol. 5, no. 19, pp. 44-51, 2013.

[14] A. Mostafa, P. Kanrai, J. Ziebuhr, and S. Pleschka, "Improved dual promotor-driven reverse genetics system for influenza viruses," Journal of Virological Methods, vol. 193, no. 2, pp. 603610, 2013.

[15] G. Neumann, T. Watanabe, H. Ito et al., "Generation of influenza A viruses entirely from cloned cDNAs," Proceedings of the National Academy of Sciences of the United States of America, vol. 96, no. 16, pp. 9345-9350, 1999.

[16] E. Hoffmann and R. G. Webster, "Unidirectional RNA polymerase I-polymerase II transcription system for the generation of influenza A virus from eight plasmids," Journal of General Virology, vol. 81, no. 12, pp. 2843-2847, 2000.

[17] H. A. Cabrera-Fuentes, M. Aslam, M. Saffarzadeh et al., "Internalization of Bacillus intermedius ribonuclease (BINASE) induces human alveolar adenocarcinoma cell death," Toxicon, vol. 69, pp. 219-226, 2013.

[18] W. Ullmer and B. L. Semler, "Diverse strategies used by picornaviruses to escape host RNA decay pathways," Viruses, vol. 8, no. 12, p. E335, 2016.

[19] B. Faburay and J. A. Richt, "Short interfering RNA inhibits rift valley fever virus replication and degradation of protein kinase R in human cells," Frontiers in Microbiology, vol. 7, no. 1889, 2016.

[20] C. Li, Z. Wang, Y. Cao et al., "Screening for novel small molecule inhibitors targeting the assembling of influenza virus polymerase complex by a BiLC-based reporter system," Journal of Virology, vol. 91, no. 5, 2016.

[21] T. Hermann, "Small molecules targeting viral RNA," Wiley Interdisciplinary Reviews: RNA, vol. 7, no. 6, pp. 726-743, 2016. 

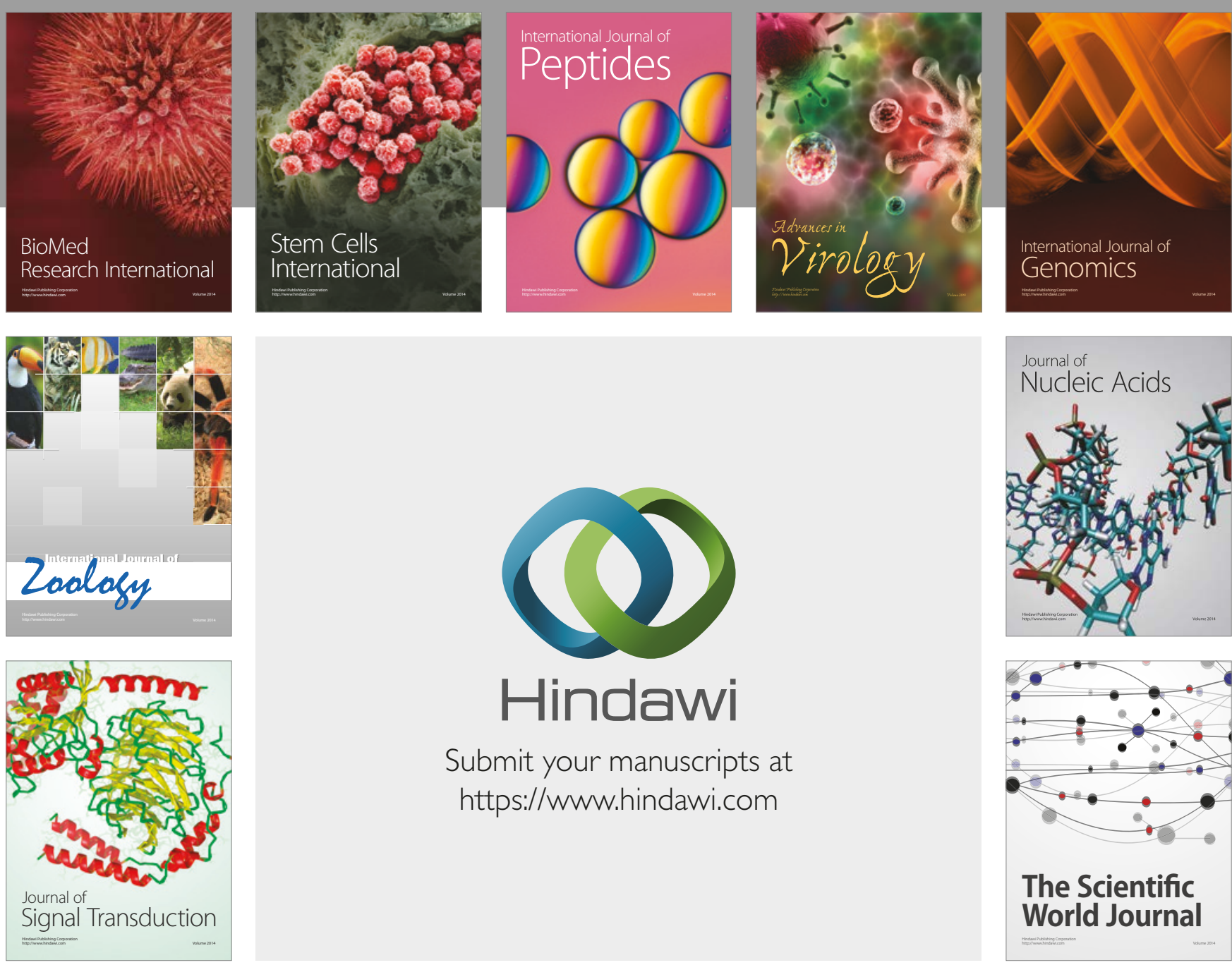

Submit your manuscripts at

https://www.hindawi.com
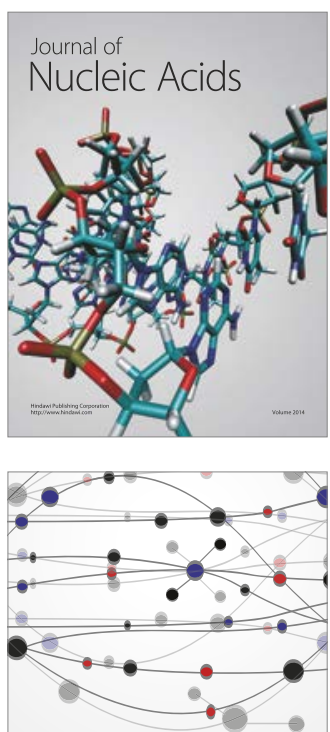

The Scientific World Journal

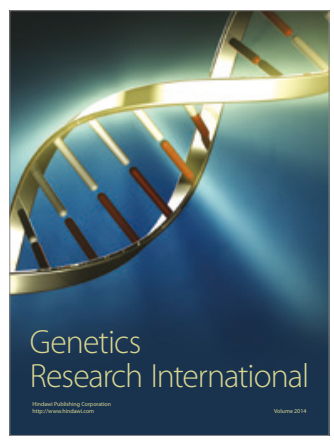

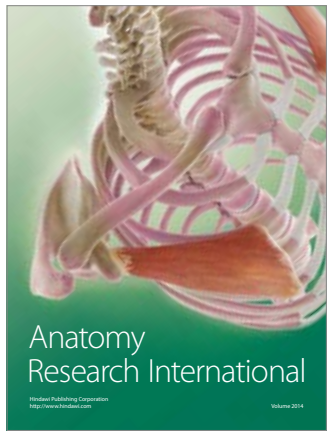

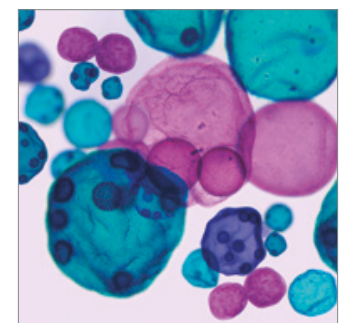

International Journal of Microbiology
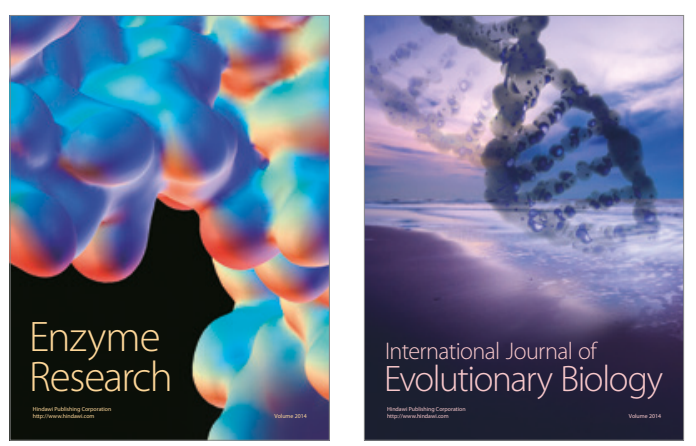
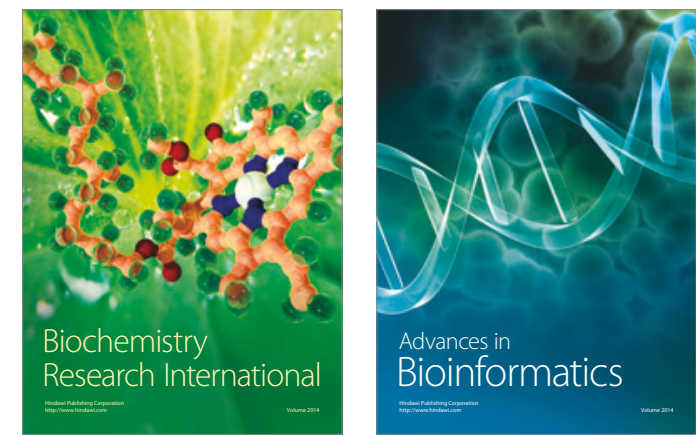

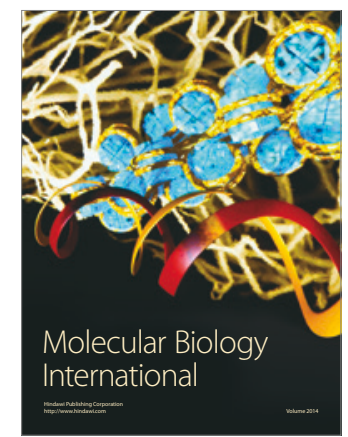

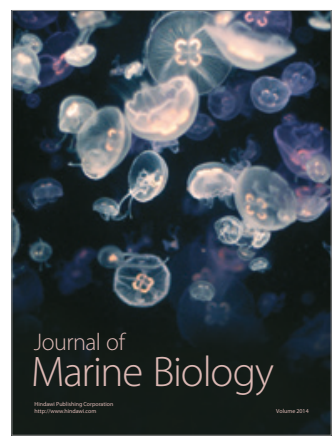

